\title{
NON-CONVENTIONAL SOLID STATE JOINING OF STRUCTURAL
}

\section{MATERIALS}

\author{
Shanthala $K^{1}$, T.N. Sreenivasa ${ }^{2}$ \\ ${ }^{1}$ Mechanical Department, AMC Engineering College Bangalore \\ ${ }^{2}$ Mechanical Department, AMC Engineering College Bangalore
}

\begin{abstract}
Joining is a process that brings two or more materials together to form continues single unit. Joining is done to facilitate design flexibility in combining the hybrid structures thereby increase the functionality and produce so called smart structures. Solid state joining produces coalescence at temperatures below the melting point of base materials. The present paper examines two of the non-conventional solid state joining processes, thermo-hydrogenated diffusion bonding and electromagnetic welding.
\end{abstract}

\section{INTRODUCTION}

Joining technology is vital for a broad range of hybrid structures. It combines the advantages of multi material, increases the design flexibility and functionality of large number of industrial products. The process of joining is normally done by mechanical fastening, adhesive bonding and welding.

Welding can be achieved by the application of heat or pressure or both. An additional metal may or may not be used in the welding process. Conventional welding process is established by fusion of the base materials where an external heat source is used. There is a bulk melting of base metals at the joint area. Especially dissimilar materials may produce fragile intermetallic phases leading to degradation of mechanical joints at elevated temperature. Solid state joining process involves low temperature and often the welding is established at very short duration. Thus, dissimilar materials are easily joined by solid state joining techniques. Solid state joining involves either the use of deformation or diffusion and limited deformation producing a high-quality joint between similar as well as dissimilar materials [1]. Two non-conventional solid state process, thermo-hydrogen processed diffusion bonding and electromagnetic welding are detailed in the paper.

Temporary alloying of titanium is called as thermo hydrogen processing (THP) and is extensively employed in enhancing both fabricability and mechanical behaviour of titanium (Ti) alloys [2]. Hydrogen though deleterious on the mechanical properties, can also be used in some cases to enhance the processing of Ti alloys. Alloying of hydrogen results in the formation of more ductile $\beta$ phase and decreases the $\beta$ transition temperature. This aspect is used mainly for processing $\mathrm{Ti}$ at lower temperature. Diffusion bonding, a solid-state pressure welding is used for joining hydrogenated CP-Ti to 304 stainless steel.

Electromagnetic welding (EMW) is a type of solidstate impact welding which uses repulsive Lorenz force created between the electromagnetic coil and a flyer material [3]. The flyer hits on a target material at very high impact velocity and yields to form bonding between flyer and target. Aluminium is joined to 304 stainless steel by EMW.

\section{EXPERIMENTAL DETAILS}

Commercial pure titanium (CP-Ti) is used for electrolytic charging of hydrogen and subsequently joined to hot-rolled 304 stainless steel (SS) by diffusion bonding. Schematic diagram of the diffusion setup is shown in the Fig 1.

Hydrogen charging on CP-Ti is carried out by electrolytic charging using platinum as anode with sulphuric acid electrolyte bath, at constant current density of $0.2 \mathrm{~A} / \mathrm{cm}^{2}$. Microstructure of the hydrogen layer at the surface of titanium is shown in the Fig. 1a.

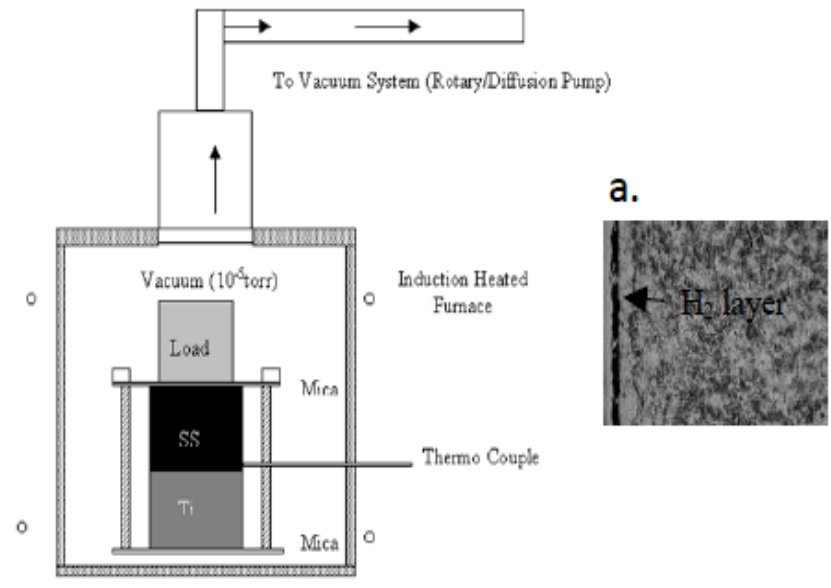

Fig 1 Schematic layout of diffusion bonding setup a.) Microstructure of hydrogenated titanium

Rectangular pieces of $10 \times 10 \times 0.5 \mathrm{~mm}$ is cut from hydrogen charged CP-Ti, as received CP-Ti and 304 SS sheets. Sandwich type diffusion couples are prepared by hydrogenated CP-Ti with SS and as received CP-Ti with SS. The die assembly is tightened under a contact pressure of 
$10 \mathrm{MPa}$ in a hydraulic press and heated in a dynamic vacuum of $10-5$ torr, for $2 \mathrm{hrs}$ at $600^{\circ} \mathrm{C}, 750^{\circ} \mathrm{C}$ and $850^{\circ} \mathrm{C}$ temperature.

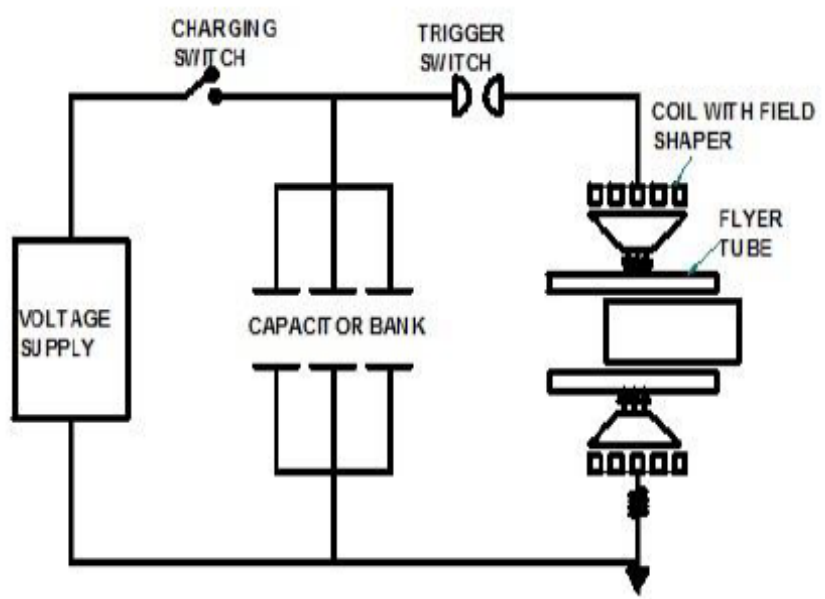

Fig 2 Schematic layout of Electromagnetic welding setup [4].

Electromagnetic welding experiment is done to join commercially available 6061 aluminium tube of $50 \mathrm{~mm}$ diameter to 304 stainless steel using $40 \mathrm{~kJ} / 20 \mathrm{kV}$ multi turn electromagnetic welding machine at Bhabha Atomic Research Centre. The experimental current input used is $200 \mathrm{kA}$ at frequency $10 \mathrm{kHz}$. Schematic layout of the electromagnetic welding setup is shown in the Fig 2.

\section{RESULTS AND DISCUSSION}

\subsection{Evaluation Diffusion Bonded Samples}

Optical micrographic examination (Fig.3) of the diffusion bonding of the un-hydrogenated as received CP-Ti with SS at $600^{\circ} \mathrm{C}$ showed a complete debonding at the interface. Whereas the interface of the hydrogenated CP-Ti with SS showed a complete bonding at interface with some voids. This indicated that it is possible to achieve bonding at $600^{\circ} \mathrm{C}$ which is normally difficult by conventional diffusion. The voids indicated traces of hydrogen may be present in the samples.

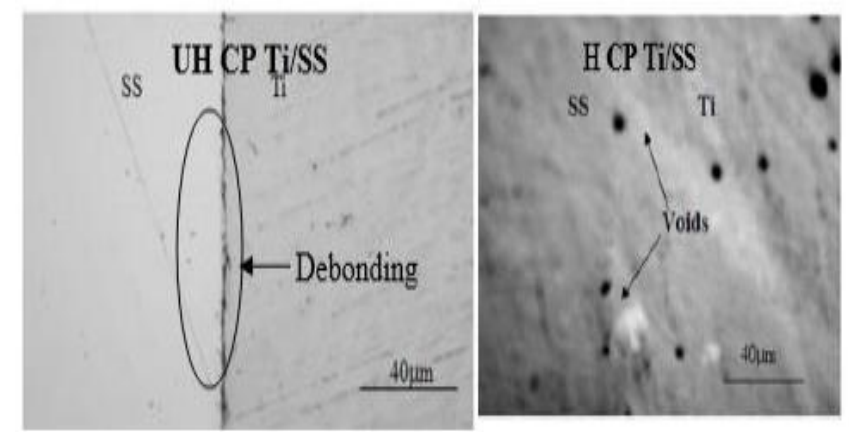

Fig 3. Optical micrograph of samples a) unhydrogenated $\mathrm{CP}-\mathrm{Ti} / \mathrm{SS}$ b) hydrogenated CP-Ti /SS

Further examination of the samples at $750^{\circ} \mathrm{C}$ (Fig. 4a.) by electron probe micro analyser indicated a very good bonding with large interface reaction layer of Widmanstaten $\alpha-\beta$ structure and parent unaffected $\mathrm{Ti}$. in hydrogenated $\mathrm{CP}-\mathrm{Ti}$ with SS. The chemical analysis represented in the concentration profile (Fig. 4b) also indicated the presence of large width of interface layers. Traces of hydron are absent showing no voids, that hydrogen has been removed at $750^{\circ} \mathrm{C}$ from the titanium during the bonding at the vacuum pressure . The bonding is visible in unhydrogenated CP-Ti with SS at $750^{\circ} \mathrm{C}$. But it has lesser reaction zone with some intermetallic (Fig. 5a). Chemical analysis shown in the Fig. 5 b confirmed lesser diffusion zone in the bonded area.

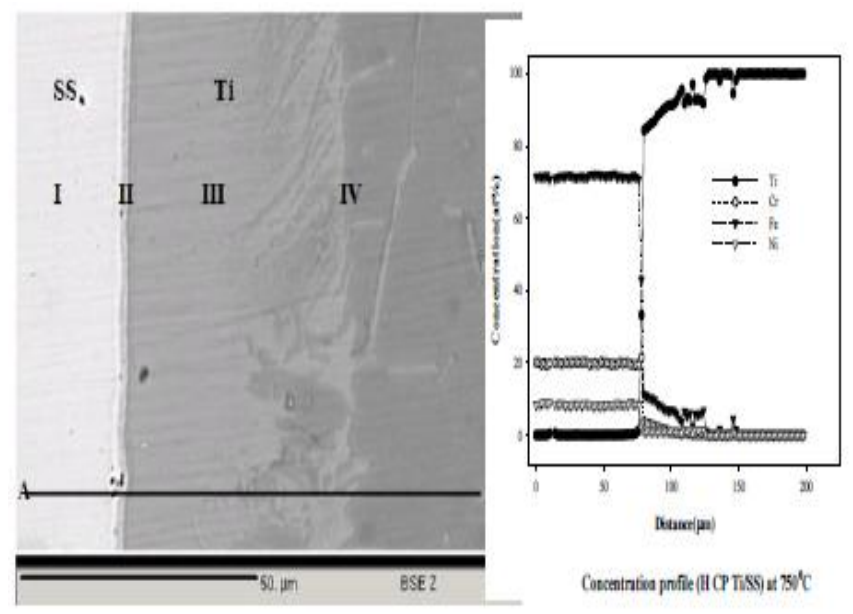

Fig 4. a) Interface microstructure at $750{ }^{\circ} \mathrm{C}$ for hydrogenated CP-Ti /SS b) Concentration profile
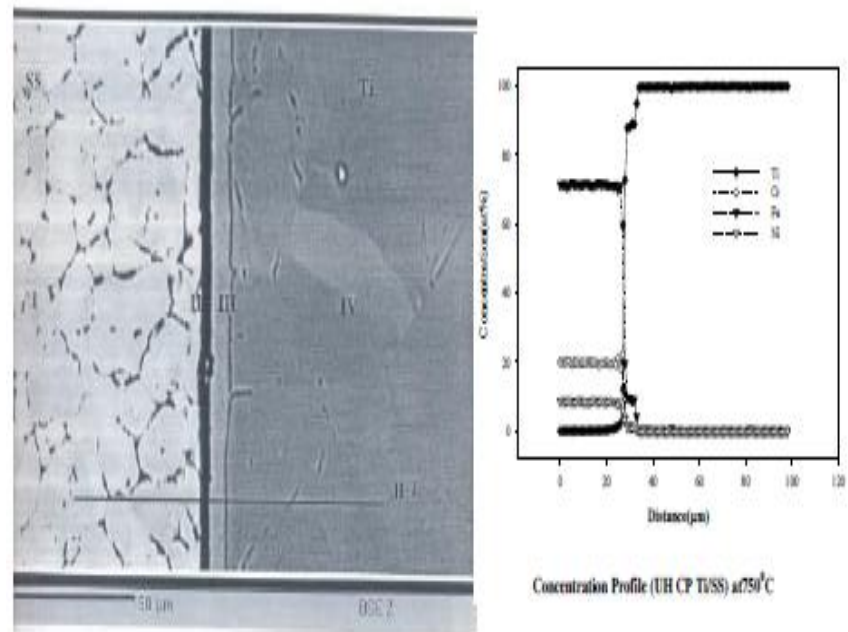

Fig 5. a) Interface microstructure at $750{ }^{\circ} \mathrm{C}$ for unhydrogenated $\mathrm{CP}-\mathrm{Ti} / \mathrm{SS}$ b) Concentration profile

\subsection{Evaluation of Electro Magnetic Welded}

\section{Samples}

The interface microstructure of aluminium AA6061 bonded to stainless steel (Fig.6) showed a complete bonding with Helium leak rate for the sample in the range of 1 to $3 \times 10-8$ torr- $1 / \mathrm{s}$. Leak tightness at the interface signifies that EMW process offers a strong promise for end closure joint.There no traces of intermetallics which are normally present in the conventional bonding. 


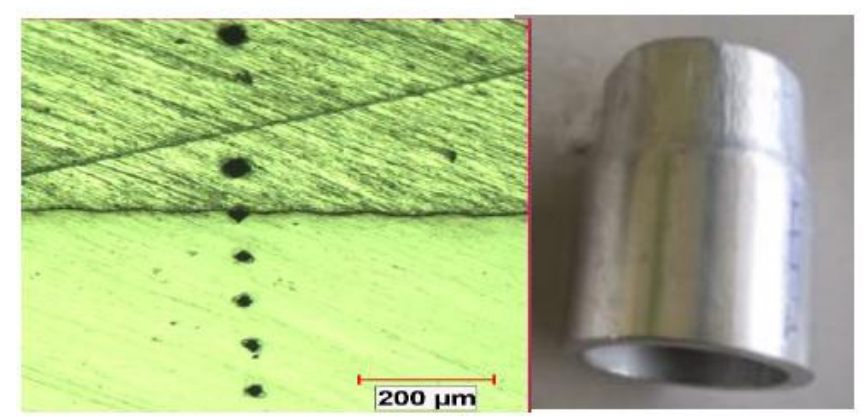

Fig 6: Microstructure of electromagnetic welded aluminium/SS. b) Welded samples

\section{CONCLUSION}

Two non-conventional solid state bonding process are successfully carried to join dissimilar materials.

a) Themo hydrogenated commercial pure titanium alloys could be joined to stainless steel with lower temperatures when compared to un-hydrogenated commercial pure titanium to stainless steel.

b) Electromagnetic welding of aluminium to steel had a characteristic wavy interface at the bonded region. The result of helium leak test also indicating tightness at the interface.

\section{ACKNOWLEDGEMENT}

The authors gratefully acknowledge the authorities of APPD, BARC for giving permission and support extended by Dr. Archana Sharma, EMM team of PPSS, APPD, Bhabha Atomic Research Center while conducting the EMW experiments. The authors also thank Dr. Bhanumurthy, BARC for guiding and extending support while conducting diffusion bonding experiments.

\section{REFERENCES}

[1] Paul Kah, Raimo Suoranta, Jukka Martikainen, Carl Magnus, "Techniques for joining dissimilar materials:Metals and Polymers" Rev. Adv. Mater. Sci. 36 (2014), pp 152-164.

[2] K Shanthala, Jagannath Nayak, K Bhanumurthy, "Diffusion Bonding of CP Ti/304SS through TiH2 Interface Layer" ICCOMIM - 2012, 11-13 July, (2012), pp 467-472.

[3] S.D.Kore, P.P.Date, S.V.Kulkarni "Effect of process parameters on electromagnetic impact welding of aluminium sheets" International Journal of Impact Engineering, vol 34, (2007) pp 1327- 1341.

[4] K.Shanthala and T.N.Sreenivasa, "Review on electromagnetic welding of dissimilar materials", Frontier of Mechanical Engineering, Vol 11, Issue 4, (2016) , pp 363-373, DOI 10.1007/s11465-0160375-0 